\title{
The impact of COVID-19 on familial Mediterranean fever: a nationwide study
}

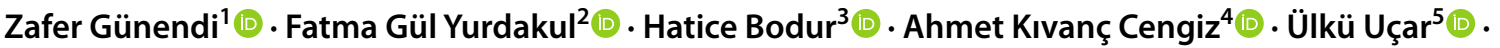

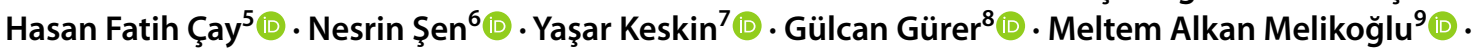

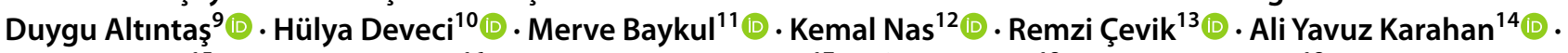

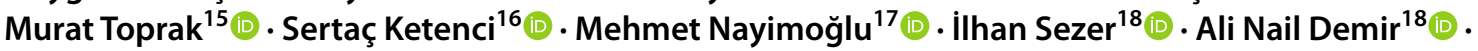

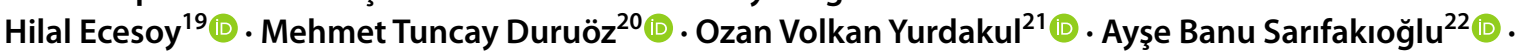 \\ Şebnem Ataman ${ }^{23}$
}

Received: 16 April 2021 / Accepted: 14 May 2021 / Published online: 25 May 2021

(c) The Author(s), under exclusive licence to Springer-Verlag GmbH Germany, part of Springer Nature 2021

\begin{abstract}
The study aimed to evaluate the impact of the coronavirus disease 2019 (COVID-19) in patients with familial Mediterranean fever (FMF) and to assess the relationships between FMF characteristics and severe COVID-19 outcomes such as hospitalization. The study was planned within a national network of 21 different centers. Demographics, FMF-related clinical and genetic characteristics, and COVID-19 outcomes were obtained. A total of 822 patients with FMF (mean age of 36 years) were included in the study. Fifty-nine of them (7\%) had a COVID-19 diagnosis confirmed by real-time PCR test or chest CT findings. Most FMF patients with COVID-19 (58) had mild and moderate disease activity. All patients were on colchicine treatment. However, 8 of them (13.6\%) were not compliant with colchicine use and 9 of them (15.3\%) were colchicine resistant. Twelve FMF patients with COVID-19 were hospitalized. There were 4 patients requiring oxygen support. COVID-19 related complications were observed in 2 patients ( 1 thromboembolism, 1 acute respiratory distress syndrome). Hospitalized COVID-19 patients with FMF were older than non-hospitalized patients (median ages: 51 and 31 years, respectively; $p$ : 0.002). Other FMF-related characteristics were similar between the groups. FMF-related characteristics were not found to be associated with poor outcomes in COVID-19. Thus, FMF may not be a risk factor for poor COVID-19 outcomes.
\end{abstract}

Keywords COVID-19 Familial Mediterranean fever $\cdot$ Rheumatic diseases $\cdot$ Colchicine $\cdot$ Hospitalization $\cdot$ Poor outcomes

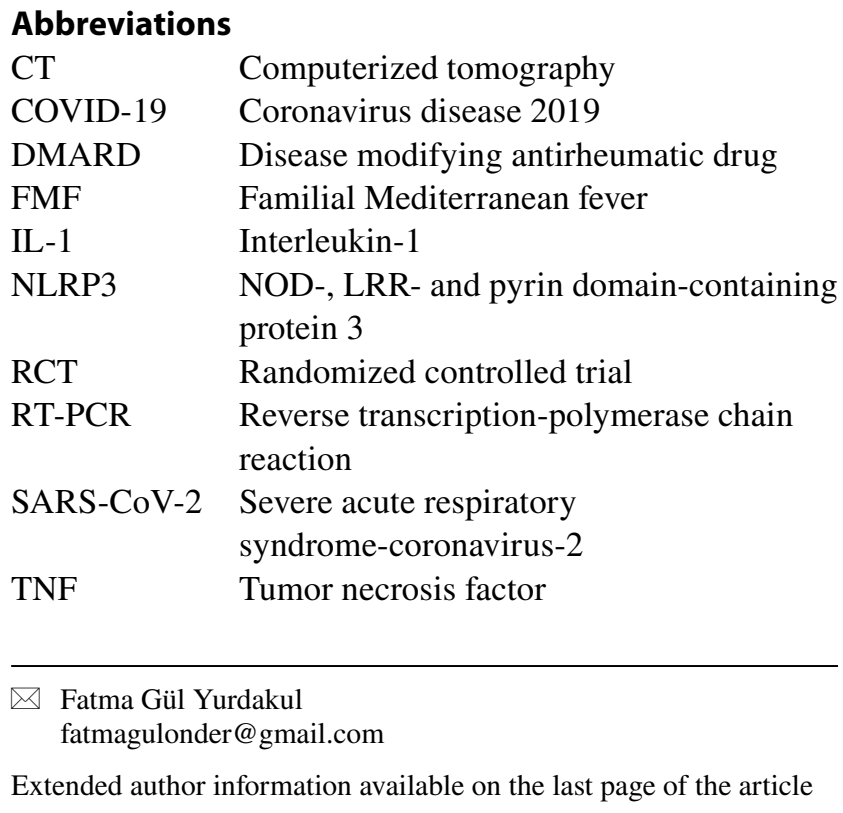

\section{Introduction}

The novel coronavirus disease 2019 (COVID-19) is a pandemic that has a detrimental effect on public health worldwide. It first appeared in China in December 2019 and spread all over the world in a short time. The causative microorganism is severe acute respiratory syndromecoronavirus-2 (SARS-CoV-2) [1]. This virus mainly causes respiratory system symptoms like dyspnea and dry cough. However, other symptoms such as headache, thromboembolism, and diarrhea are not uncommon. The disease may progress to critical levels in some patients. Respiratory and heart failure, sepsis, septic shock are the characteristics of critical illness. The diagnosis is established by reverse transcription-polymerase chain reaction (RT-PCR) assay from upper respiratory tract swab specimen and typical computed tomography findings including bilateral lung consolidation and ground-glass opacities [2,3]. Severe disease and critical 
illness account for approximately $20 \%$ of all patients [4]. Older age, obesity, hypertension, diabetes mellitus, chronic lung or kidney disease, and cardiovascular disease have been identified as risk factors for poor outcomes in COVID-19 [2]. Although rheumatic diseases were not considered as a risk factor for severe COVID-19 early in the pandemic [5], the accumulated data showed that rheumatic diseases, especially those with moderate/high disease activity, are also at risk for severe COVID-19 [6].

Familial Mediterranean fever (FMF) is an autoinflammatory rheumatic disease that is prevalent in the Mediterranean basin. Turkey is among the countries where the disease appears frequently. Most patients are from the Eastern Anatolia and the Eastern Black Sea Region [7]. The innate immune system that plays a critical role in the pathogenesis of FMF is also essential in antiviral defense [8]. It is thought that some viral protein particles increase COVID-19 severity via prolonged and excessive activation of the innate immune system. In an experimental study, Siu et al. found that "SARS-CoV open reading frame 3 a accessory protein" activates NOD-, LRR- and pyrin domain-containing protein 3 (NLRP3) inflammasome, a multiprotein component of the innate immune system, and may cause a cytokine storm by this way [9]. Colchicine is an anchor drug in the management of FMF. The mechanism of action is inhibition of microtubule polymerization and NLRP3 inflammasome. Therefore, colchicine may have a potential benefit in severe COVID-19. When all the information above is taken into consideration, the progression of COVID-19 and the risk factors for severe outcomes in patients with FMF arouse interest.

In this study, we aimed to investigate the rate of COVID19 and to assess the relationship between FMF features and Covid-19 severe outcomes such as hospitalization, the need for oxygen support, and death in patients with FMF.

\section{Materials and methods}

A multicenter cross-sectional study was conducted between 1st June 2020 (the end of the first peak in Turkey) and 28th February 2021. Approvals from Ankara City Hospital Ethics Committee (Approval date/no:16.04.2020/E1-20-440) and the general directorate of health services of Turkey were obtained. The patients were informed about the study, and written informed consents were received.

A national network database system (https://www.trasdnetwork.org), emerged by the Turkish League Against Rheumatism, was used for the data collection. 21 centers (26 researchers) from different regions of Turkey participated in the study. We included the patients with FMF ( $\geq 18$ years) diagnosed by the Tel Hashomer criteria, as revised by Livneh et al. [10]. Patients who have a history of transplantation, malignancy within the last 5 years, immunodeficiency diseases, or using medications that cause immunodeficiency were excluded.

Electronic case report forms in the network database system regarding demographics, clinics, genetic test results, and COVID-19 status of the patients who applied to rheumatology and physical medicine and rehabilitation outpatient clinics at research centers were filled out by the researchers during routine clinical practice.

Clinical data included disease age (years), use of medications [colchicine, interleukin-1 (IL-1) inhibitors, tumor necrosis factor (TNF) inhibitors], regular colchicine use, colchicine resistance (defined as two or more attacks in the last 6 months despite regular colchicine use for 12 months) [7], disease severity, presence or absence of amyloidosis, chronic renal failure, dialysis status, comorbidities. Disease severity was assessed with a scoring system developed by Pras et al. [11]. Disease severity scores range between 2 and 19 points ( $\geq 10$ points indicate severe disease, $6-10$ points indicate moderate disease, and $\leq 5$ points indicate mild disease).

According to the previous genetic mutations, patients were divided into three groups [homozygous (same mutation in two alleles), heterozygous (mutation in one allele), and compound heterozygous (different mutations in two alleles)].

Data about the COVID-19 status included the previous history of COVID-19 diagnosis, if they had COVID-19 diagnosis; diagnosis methods [positive SARS-CoV-2 RT-PCR test, typical chest computerized tomography (CT) images], medications used in COVID-19 management, outcomes (recovery without hospitalization, hospitalization, need for oxygen support, death), complications associated with COVID-19 (acute respiratory distress syndrome, sepsis, renal failure, myocarditis, macrophage activation syndrome, disseminated intravascular coagulation, thromboembolism, secondary infection).

Statistical analysis was performed using the SPSS program (V.21) after exporting data from the national network database system. Results were expressed as means (standard deviations), mean differences (95\% confidence intervals), medians (interquartile ranges), numbers, and percentages. The normality of continuous variables was checked by the Kolmogorov-Smirnov test. Comparisons between groups were performed by Independent Samples t-test for normally distributed continuous variables, and Mann-Whitney $U$ test for non-normally distributed continuous variables. The Chi-Square test and Fisher's exact test were used for testing relationships between categorical variables. Statistical significance was set at $p<0.05$. 


\section{Results}

A total of 822 patients with FMF (mean age of 36 years) were included in the study. The mean disease duration was 9 years. Most patients (416) had moderate disease activity, 361 had mild, and few patients (45) had severe disease activity. MEFV gene analysis was conducted in 612 patients. A total of 166 homozygous and 432 heterozygous mutations were detected. All patients were on colchicine treatment. However, 108 of them were not compliant with colchicine use. There were 128 patients with colchicineresistant FMF. Other demographic and clinical features of patients are shown in Table 1.

A total of 59 patients with FMF had a COVID-19 diagnosis confirmed by real-time PCR test or chest CT findings. Twelve of them were hospitalized. There were 4 patients requiring oxygen support. COVID-19-related complications were observed in 2 patients ( 1 thromboembolism, 1 acute respiratory distress syndrome). No death occurred. Patients' demographics, clinical features associated with FMF and COVID-19 are indicated in Table 1.

In the comparison of demographics, FMF features, and COVID-19 outcomes between hospitalized and non-hospitalized patients, hospitalized patients were significantly older than non-hospitalized patients (median ages: 51 and 31 years, respectively; p:0.002). Other characteristics were the same between the groups (Table 2).

Detailed genotype analysis was obtained in 44 COVID19 patients with FMF. There was no difference regarding allele frequencies in MEFV mutations between hospitalized and non-hospitalized patients (Table 3).

\section{Discussion}

In our cohort, we found the COVID-19 rate as $7 \%$ in patients with FMF. Twenty percent of infected patients were hospitalized, $6.7 \%$ needed oxygen support, $3.4 \%$ developed complications ( 1 thromboembolism, 1 acute respiratory distress syndrome), none died. The mean age of hospitalized COVID-19 patients with FMF was higher than non-hospitalized patients. Other demographics and FMF-related features were similar between hospitalized and non-hospitalized patients.

First studies during pandemic did not define inflammatory rheumatic diseases as comorbidities increase the risk of COVID-19 severe outcomes [12,13]. D'Silva et al. found similar symptoms and rates of hospitalization and mortality in COVID-19 patients with rheumatic disease and without rheumatic disease. However, admission rates to intensive care unit and mechanical ventilation were
Table 1 Demographics, disease characteristics, comorbidities, genetic analysis and data about COVID-19 of patients with FMF

\begin{tabular}{|c|c|c|}
\hline & $\begin{array}{l}\text { All FMF } \\
\text { pateints } \\
n=822\end{array}$ & $\begin{array}{l}\text { FMF } \\
\text { Patients } \\
\text { with } \\
\text { COVID-19 } \\
n=59\end{array}$ \\
\hline Age (years), mean (SD) & $35.6(12.0)$ & $36.7(12.4)$ \\
\hline Women, $n(\%)$ & $517(62.9)$ & $40(67.80)$ \\
\hline \multicolumn{3}{|l|}{ Education level, $n(\%)$} \\
\hline Illiterate & $22(2.6)$ & $2(3.4)$ \\
\hline Elementary school & $326(39.7)$ & $24(40.7)$ \\
\hline High school & $248(30.2)$ & $13(22.0)$ \\
\hline University & $226(27.5)$ & $20(33.9)$ \\
\hline $\begin{array}{l}\text { Consanguineous marriage of parents, } \\
n(\%)\end{array}$ & $174(21.2)$ & $12(20.3)$ \\
\hline Smoking habit, $n(\%)$ & $204(24.8)$ & $12(20.3)$ \\
\hline Alcohol habit, $n(\%)$ & $71(8.6)$ & $8(13.6)$ \\
\hline FMF in first-degree relatives, $n(\%)$ & $89(10.8)$ & $3(5.1)$ \\
\hline Diagnosis age (years), mean (SD) & $9.1(7.0)$ & $10.4(7.6)$ \\
\hline \multicolumn{3}{|l|}{ Comorbidities, $n(\%)$} \\
\hline Diabetes mellitus & $10(1.2)$ & $1(1.7)$ \\
\hline Hypertension & $64(7.8)$ & $9(15.2)$ \\
\hline Cardiovascular disease & $2(0.2)$ & $1(1.7)$ \\
\hline Lung disease (COPD) & $12(1.5)$ & $0(0)$ \\
\hline Amyloidosis, $n(\%)$ & $22(2.7)$ & $0(0)$ \\
\hline Phenotype II, $n(\%)$ & $20(2.4)$ & $1(1.7)$ \\
\hline \multicolumn{3}{|l|}{ Disease severity, $n(\%)$} \\
\hline Mild & 361 (43.9) & $25(42.4)$ \\
\hline Moderate & $416(50.6)$ & $33(55.9)$ \\
\hline Severe & $45(5.5)$ & $1(1.7)$ \\
\hline MEFV gene analysis, $n(\%)$ & $612(74.4)$ & $41(69.5)$ \\
\hline Negative & $14(2.3)$ & $1(2.4)$ \\
\hline Homozygote mutations & $166(27.1)$ & $15(36.6)$ \\
\hline Heterozygote mutations & $300(49.0)$ & $17(41.5)$ \\
\hline Compound heterozygote & $132(21.6)$ & $8(19.5)$ \\
\hline \multicolumn{3}{|l|}{$\begin{array}{l}\text { Non-compliance with colchicine use, } \\
n(\%)\end{array}$} \\
\hline Colchicine resistance, $n(\%)$ & $108(13.1)$ & $8(13.6)$ \\
\hline Non-colchicine drugs, $n(\%)$ & $128(15.6)$ & $9(15.3)$ \\
\hline Anakinra & $20(2.4)$ & $1(1.7)$ \\
\hline Canakinumab & $16(1.9)$ & $1(1.7)$ \\
\hline Rilonacept & $1(0.1)$ & $0(0)$ \\
\hline TNF inhibitors & $25(3.0)$ & $1(1.7)$ \\
\hline Chronic renal failure, $n(\%)$ & $11(1.3)$ & $0(0)$ \\
\hline Dialysis, $n(\%)$ & $6(0.7)$ & $0(0)$ \\
\hline \multicolumn{3}{|l|}{ COVID-19 diagnosis methods, $n(\%)$} \\
\hline Positive PCR test & & 52 \\
\hline Positive CT findings & & 8 \\
\hline \multicolumn{3}{|l|}{ COVID-19-related medications, $n(\%)$} \\
\hline Antiviral agents & & 47 \\
\hline Antibacterial agents & & 7 \\
\hline Antimalarial drugs & & 22 \\
\hline
\end{tabular}


Table 1 (continued)

\begin{tabular}{lll}
\hline & $\begin{array}{l}\text { All FMF } \\
\text { pateints } \\
n=822\end{array}$ & $\begin{array}{l}\text { FMF } \\
\text { Patients } \\
\text { with } \\
\text { COVID-19 } \\
n=59\end{array}$ \\
& 2 \\
\hline Corticosteroids & 2 \\
Anticoagulants & \\
COVID-19 severe outcomes, $n(\%)$ & $12(20.3)$ \\
Hospitalization & $4(6.8)$ \\
Oxygen support & $2(1 \mathrm{TE}, 1$ \\
Complications & ARDS) \\
& & $(3.4)$ \\
Death & $0(0)$ \\
\hline
\end{tabular}

$F M F$ familial Mediterranean fever, $S D$ standard deviation, $C O P D$ chronic obstructive pulmonary disease, TNF tumor necrosis factor, COVID coronavirus disease, TE thromboembolism, ARDS acute respiratory distress syndrome

threefold higher in patients with a rheumatic disease [14]. The reason for the increased risk for intensive care admission is not apparent. The immunosuppressives which are used in rheumatic diseases may be a potential explanation. According to this result, the authors highlighted the importance of close monitoring of rheumatic patients with COVID-19. Another observational study from Spain showed that the only risk factors for hospitalization related to COVID-19 are increased age and systemic autoimmune conditions in patients with inflammatory rheumatic diseases [15]. Similarly, in a matched cohort study, systemic connective tissue diseases (systemic lupus erythematosus, Sjogren's syndrome, systemic sclerosis, polymyalgia rheumatica, vasculitis) regardless of immunosuppressive therapies were found as a risk factor for poor COVID-19 outcomes [16].

The COVID-19 Global Rheumatology Alliance reported the data from the first 600 inflammatory disease patients (majority with rheumatoid arthritis) with COVID19 in July 2020 [17]. Older age, comorbidities such as diabetes, cardiovascular disease, chronic renal insufficiency, and higher doses of prednisone ( $\geq 10 \mathrm{mg} /$ day) were found as risk factors for COVID-19 hospitalization. It was also found that biologic or targeted synthetic disease modifying antirheumatic drug (DMARD)s are associated with a lower risk of hospitalization. This global cooperation recently reported the data on a greater number of inflammatory rheumatic disease patients with COVID-19. They found that moderate/high disease activity was associated with COVID-19-related death [6]. According to their result, it is crucial to control disease activity in patients with rheumatic disease in the current pandemic. A recent metaanalysis found high rates of oxygen support and mortality among COVID-19 infected patients with a rheumatic disease (33\%, 7\%, respectively) [18]. Therefore, rheumatic diseases are now considered a risk factor for severe outcomes in COVID-19.

All the studies mentioned above do not include familial Mediterranean fever, the most common form of monogenic autoinflammatory diseases that share a common pathogenetic pathway with COVID-19. Unlike these studies, we found only increased age as a possible associated factor with COVID-19 related hospitalization in patients with FMF. The defined risk factors for COVID-19 hospitalization in other studies, such as comorbidities and disease severity, were not different between hospitalized and non-hospitalized COVID19 patients with FMF. Also, the rate of biologic DMARD use was the same between groups. The reason why FMF differs from other inflammatory rheumatic diseases may be explained with the genetic background and divergent pathogenetic pathways.

The initial phase of the COVID-19 is transmission and replication of the virus. Then, the inflammatory phase begins. The first antiviral response is initiated by the innate immune system. Secretion of type 1 interferons and proinflammatory cytokines occurs in this response [8]. The inflammatory phase may cause rapid deterioration. Host immune response is generally able to improve inflammatory damage. Sometimes exaggerated immune response, also called hyperinflammation, occurs and severe systemic damage develops. Although the reason for hyperinflammation is not known, host genetic risk factors are suspected [19].

NLRP3 inflammasome is probably associated with hyperinflammation developed in COVID-19. It is also important in the pathogenesis of FMF. It was suggested that impairment in the regulation of NLRP3 inflammasome could lead to a complex immune response in viral infections [20]. Stalla et al. hypothesized that the dysregulation between Pyrin and NLRP3 inflammasome might alter the balance between protective inflammation against virus and hyperinflammation [8]. Therefore, the frequency and severity of SARS-CoV-2 infection in FMF are intriguing. Bourguiba et al. found similar incidence rates of COVID-19 in FMF patients (8\%) and the general population (11\%) in a French endemic area [21]. They also reported that FMF patients with severe SARSCoV-2 infection have known risk factors like increased age, obesity, and hypertension. Accordingly, we found a similar COVID-19 incidence rate (7\%) and low rates of COVID19-related severe outcomes like hospitalization and oxygen support in FMF patients. Furthermore, no mortality was observed. According to both Bourguiba's and our study, FMF is probably not a risk factor for severe COVID-19. Furthermore, Haslak et al. found that monogenic autoinflammatory diseases, predominantly FMF, in pediatric patients are not associated with increased COVID-19 and the severe disease course [22]. 
Table 2 Comparison of demographics, FMF characteristics and comorbidities between hospitalized and non-hospitalized FMF patients with COVID-19

\begin{tabular}{|c|c|c|c|c|}
\hline & Hospitalized ( $n: 12)$ & Non-hospitalized ( $n: 47)$ & Mean difference $(95 \% \mathrm{CI})$ & $p$ \\
\hline \multicolumn{5}{|l|}{ Age (years) } \\
\hline Mean (SD) & $46.7 \pm 12.1$ & $33.1 \pm 10.9$ & & \\
\hline Median (IQR) & $50.5(40.0-53.4)$ & $31.0(24.0-42.0)$ & $13.6(6.2-20.8)$ & 0.002 \\
\hline Women, $n(\%)$ & $8(66.7)$ & $31(66.0)$ & & 0.922 \\
\hline Smoking habit, $n(\%)$ & $2(16.7)$ & $10(21.3)$ & & 0.645 \\
\hline Alcohol habit, $n(\%)$ & $2(16.7)$ & $6(12.8)$ & & 0.089 \\
\hline Comorbidities, $n(\%)$ & $4(33.3)$ & $7(14.9)$ & & \\
\hline Diabetes mellitus & 1 & 0 & & 0.196 \\
\hline Hypertension & 3 & 6 & & \\
\hline Cardiovascular Disease & 0 & 1 & & \\
\hline \multicolumn{5}{|l|}{ Disease age (years) } \\
\hline Mean (SD) & $13.8 \pm 9.1$ & $10.1 \pm 7.4$ & $3.7(-2.4-9.7)$ & 0.270 \\
\hline Median (IQR) & $9.5(8.2-21.8)$ & $8.5(3.0-14.2)$ & & \\
\hline Disease severity, $n(\%)$ & & & & 0.908 \\
\hline Mild & $5(41.7)$ & $20(42.6)$ & & \\
\hline Modarate & $7(58.3)$ & $26(55.3)$ & & \\
\hline Severe & $0(0)$ & $1(2.1)$ & & \\
\hline Phenotype II, $n(\%)$ & $0(0)$ & $1(2.1)$ & & 0.828 \\
\hline $\begin{array}{l}\text { Non-compliance with colchicine } \\
\text { use, } n(\%)\end{array}$ & $2(16.7)$ & $6(12.8)$ & & 0.089 \\
\hline Colchicine resistance, $n(\%)$ & $2(16.7)$ & $7(14.9)$ & & 0.455 \\
\hline Biologics, $n(\%)$ & & & & 0.136 \\
\hline Anakinra & 0 & 1 & & \\
\hline Canakinumab & 1 & 0 & & \\
\hline TNF inhibitors & 2 & 1 & & \\
\hline MEFV gene analysis, $n(\%)$ & 10 & 31 & & 0.288 \\
\hline Negative & $1(10.0)$ & $0(0)$ & & \\
\hline Homozygote mutations & $3(30.0)$ & $12(38.7)$ & & \\
\hline Heterozygote mutations & $4(40)$ & $13(41.9)$ & & \\
\hline Compound heterozygote & $2(20)$ & $6(19.4)$ & & \\
\hline Amyloidosis & 0 & 0 & & \\
\hline Chronic renal failure & 0 & 0 & & \\
\hline Dialysis & 0 & 0 & & \\
\hline
\end{tabular}

$F M F$ familial Mediterranean fever, $S D$ standard deviation, $I Q R$ interquartile range, $T N F$ tumor necrosis factor

Although there is no particular drug that targets this virus and COVID-19, current medications, including antiviral, anti-inflammatory, and immunomodulatory drugs, have been used during the pandemic. Among these drugs, the only high-level evidence-based data in the treatment of COVID-19 belong to dexamethasone [1]. Colchicine is a synthetic drug that has been successfully using in the management of FMF. This famous drug has a well-known safety profile and low cost. Colchicine interferes recruitment of neutrophils by inhibition of microtubule formation. By this mechanism, it also has antiviral potency [23]. Colchicine may also inhibit NLRP3 inflammasome, which can be activated by SARS-CoV-2 and may probably be associated with hyperinflammation in COVID-19 [1]. According to this theoretical knowledge, colchicine may be helpful in the management of COVID-19. Low incidence rates of COVID-19 and related severe outcomes found Bourguiba's [21], and our study might be explained by the fact that all FMF patients in these studies were on colchicine treatment. Similarly, most patients with monogenic autoinflammatory disease in Haslak's [22] study were on colchicine treatment. However, all these studies had no control group and were not designed as a prospective cohort. Thus, it is difficult to make a precise conclusion about patients with monogenic autoinflammatory disease like FMF are not at increased risk for SARS-CoV-2 infection and severe COVID-19 disease course. 
Table 3 Allele frequency in MEFV gene mutations of the cohort and comparisons between hospitalized and non-hospitalized COVID-19 patients with familial Mediterranean fever

\begin{tabular}{|c|c|c|c|c|}
\hline & $\begin{array}{l}\text { Patients with } \\
\text { genetic analysis } \\
(n: 604)\end{array}$ & $\begin{array}{l}\text { Hospitalized } \\
\text { patients }(n: \\
12)\end{array}$ & $\begin{array}{l}\text { Non-hospital- } \\
\text { ized patients } \\
(n: 47)\end{array}$ & $p^{*}$ \\
\hline \multicolumn{5}{|l|}{$\mathrm{M} 694 \mathrm{~V}, n$} \\
\hline Allele 1 & 339 & 6 & 15 & 0.675 \\
\hline Allele 2 & 129 & 4 & 6 & 0.232 \\
\hline \multicolumn{5}{|l|}{ M680I, $n$} \\
\hline Allele 1 & 21 & 0 & 1 & 0.829 \\
\hline Allele 2 & 66 & 0 & 2 & 0.680 \\
\hline \multicolumn{5}{|l|}{$\mathrm{E} 148 \mathrm{Q}, n$} \\
\hline Allele 1 & 14 & 0 & 4 & 0.444 \\
\hline Allele 2 & 56 & 0 & 2 & 0.680 \\
\hline \multicolumn{5}{|l|}{$\mathrm{R} 202 \mathrm{Q}, n$} \\
\hline Allele 1 & 25 & 3 & 5 & 0.420 \\
\hline Allele 2 & 85 & 0 & 5 & 0.352 \\
\hline \multicolumn{5}{|l|}{ V726A, $n$} \\
\hline Allele 1 & 14 & 1 & 3 & 0.245 \\
\hline Allele 2 & 64 & 0 & 0 & \\
\hline \multicolumn{5}{|l|}{$\mathrm{R} 761 \mathrm{H}, n$} \\
\hline Allele 1 & 5 & 1 & 0 & 0.829 \\
\hline Allele 2 & 4 & 0 & 0 & \\
\hline
\end{tabular}

${ }^{*} p$ value for hospitalized and non-hospitalized patient groups

Some reports support the use of colchicine in the treatment of COVID-19. Scarsi et al. demonstrated that colchicine treatment is associated with better survival in patients with COVID-19 pneumonia in their controlled study [24]. However, patients on colchicine and standard treatment were younger than those on standard treatment only. Brunetti L et al. showed that colchicine caused a reduction in hospital mortality and increase in hospital discharge in patients with severe COVID-19 by day 28 [25]. This cohort study performed propensity score matching to decrease the effect of confounding factors. However, it is an observational study that has a small sample size and short duration of follow-up. Therefore, prospective randomized controlled trials (RCT) are needed to approve colchicine in the treatment of COVID-19. In the literature, there are 2 RCTs whose results have been published [26, 27]. The first study is from Greece, and the second is from Brazil. In the former study, it was found that colchicine improved time to clinical deterioration in hospitalized patients with COVID-19 [26]. However, there was no placebo arm, and patients were not blind to the treatment allocation. In the latter study, a double-blinded, placebo-controlled RCT, it was found that colchicine diminished the duration of oxygen support and hospitalization day [27].

Two papers from Turkey were published recently [28, 29]. First paper reported three FMF patients with mild
COVID-19. All patients were on colchicine treatment. Authors suggested that colchicine can positively affect the prognosis of COVID-19 in FMF patients [28]. Second paper is a retrospective cohort study from a single center. It was found that comorbidities and disease severity were numerically high in hospitalized COVID-19 patients with FMF [29]. However, without statistical analysis, no estimation could be made in terms of factors associated with poor COVID-19 outcomes in patients with FMF. In our study, we compare demographics, comorbidities, and FMF-related features between hospitalized and non-hospitalized COVID-19 patients and found similar rates of comorbidities and FMF severity in the groups. Thus, FMF severity does not seem to affect poor COVID-19 outcomes. The similar comorbidity rates between hospitalized and non-hospitalized COVID-19 patients with FMF found in our study might be due to the low comorbidity rate in FMF patients. Low comorbidities are expected in FMF patients since they have lower mean age than patients with other inflammatory rheumatic diseases such as rheumatoid arthritis. Increased age was found the sole factor that may have an association with poor COVID19 outcomes by reason of higher mean age in hospitalized COVID-19 patients with FMF.

In a genetic study, while some pyrin mutations prevalent in patients with FMF (V726A, R761H) were also found in bat species and pangolin that are hosts of SARSCoV-2, other prevalent pyrin mutations associated with FMF (M694V, M680I) were not found in these hosts [8]. The variability of pyrin mutations that are observed in the reservoir and intermediate host species of SARS-CoV-2 raises a hypothesis that a specific type of pyrin variants in patients with FMF might modulate cytokine response to the SARS-CoV-2 virus. This modulation may result in a different outcome of COVID-19; hyperinflammation or protective inflammation. In our study, most FMF patients with COVID19 had MEFV mutation analysis results. We did not find any significant difference regarding homozygous and heterozygous rates according to the MEFV mutations between hospitalized and non-hospitalized patients. Moreover, allele frequencies were similar between the two groups.

We recruited FMF patients to our study in the second half of the pandemic (from June 2021 to February 2021). There have been advances in the treatment and supportive care of COVID-19 during this period. For this reason, we might have found severe COVID-19 outcomes at low rates. According to a recent cohort study, the rates of poor outcomes related to COVID-19 in patients with rheumatic disease, such as invasive ventilation and death, have decreased over time but still remain substantial [30].

Our study has several limitations. First, this is a crosssectional study and has no control group. Therefore, no precise conclusions might be drawn. Second, 7 PCR 'negative' FMF patients were diagnosed as COVID-19 with typical 
chest computerized tomography (CT) findings. This may be a diagnostic limitation. Third, because of the low number of poor COVID-19-related outcomes (12 hospitalization, 4 oxygen support, no death), logistic regression analysis that may show predictors for poor outcomes could not be performed. However, a higher sample size than other FMF cohorts and the involvement of patients from several regions of our country that increase the generalizability of the results are important strengths of our study.

\section{Conclusion}

The COVID-19 rate was found as 7\% in patients with FMF. The low rate of COVID-19 severe outcomes was detected (20\% hospitalization, $6.7 \%$ need for oxygen support, 3.4\% complication, no death) in FMF patients. Increased age was found as a as a possible associated factor with COVID-19 related hospitalization in patients with FMF. FMF-related characteristics were not found to be associated with poor outcomes in COVID-19. Thus, FMF may not be a risk factor for poor COVID-19 outcomes. Conversely, the COVID-19 course seems to be mild in FMF patients. Nevertheless, until stronger evidence accumulates, SARS-CoV-2-infected FMF patients should be well monitored and given medical care. Controlled and long-term clinical trials are needed for more precise interpretation.

\section{Acknowledgements None declared.}

Author contributions ZG, FGY, HB, AKC, UU, HFC, NS, YK, GG, MAM, DA, HD, MB, KN, RC, AYK, MT, SK, MN, IS, AND, HK, MTD, OVY, ABS and ŞA made substantial contributions to the conception or design of the work; or the acquisition, analysis, or interpretation of data; or the creation of new software used in the work; ZG, FGY, HB, AKC, UU, HFC, NS, YK, GG, MAM, DA, HD, MB, KN, RC, AYK, MT, SK, MN, IS, AND, HK, MTD, OVY, ABS and ŞA drafted the work or revised it critically for important intellectual content; ZG, FGY, HB, AKC, UU, HFC, NS, YK, GG, MAM, DA, HD, MB, KN, RC, AYK, MT, SK, MN, IS, AND, HK, MTD, OVY, ABS and SA approved the version to be published; ZG, FGY, HB, AKC, UU, HFC, NS, YK, GG, MAM, DA, HD, MB, KN, RC, AYK, MT, SK, MN, IS, AND, HK, MTD, OVY, ABS and ŞA agreed to be accountable for all aspects of the work in ensuring that questions related to the accuracy or integrity of any part of the work are appropriately investigated and resolved.

Funding The study was not funded.

Availability of data and material Patients did not provide consent for raw data sharing during the data collection.

\section{Declarations}

Conflict of interest The authors ZG, FGY, HB, AKC, UU, HFC, NS, YK, GG, MAM, DA, HD, MB, KN, RC, AYK, MT, SK, MN, IS, AND, HK, MTD, OVY, ABS and ŞA have no conflict of interests to declare.
Ethics approval All procedures performed in the study were in accordance with the ethical standards of the institutional research committee and with the 1964 Helsinki Declaration and its later amendments (ethic committee approval date/no:16.04.2020/E1-20-440).

Consent to participate Written informed consent was obtained from all participants.

\section{References}

1. Burrage DR, Koushesh S, Sofat N (2020) Immunomodulatory drugs in the management of SARS-CoV-2. Front Immunol 13(11): 1844

2. Ladani AP, Loganathan M, Danve A (2020) Managing rheumatic diseases during COVID-19. Clin Rheumatol 39:3245-3254

3. Ye Z, Zhang Y, Wang Y, Huang Z, Song B (2020) Chest CT manifestations of new coronavirus disease 2019 (COVID-19): a pictorial review. Eur Radiol 30:4381-4389

4. Wu Z, McGoogan JM (2020) Characteristics of and important lessons from the coronavirus disease 2019 (COVID-19) outbreak in China: summary of a report of 72314 cases from the chinese center for disease control and prevention. JAMA 7(323):1239-1242

5. Mikuls TR, Johnson SR, Fraenkel L, Arasaratnam RJ, Baden LR, Bermas BL, Chatham W, Cohen S, Costenbader K, Gravallese EM, Kalil AC, Weinblatt ME, Winthrop K, Mudano AS, Turner A, Saag KG (2020) American college of rheumatology guidance for the management of rheumatic disease in adult patients during the COVID-19 pandemic: version 1. Arthritis Rheumatol 72:1241-1251

6. Strangfeld A, Schäfer M, Gianfrancesco MA, Lawson-Tovey S, Liew JW, Ljung L, Mateus EF, Richez C, Santos MJ, Schmajuk G, Scirè CA, Sirotich E, Sparks JA, Sufka P, Thomas T, Trupin L, Wallace ZS, Al-Adely S, Bachiller-Corral J, Bhana S, Cacoub P, Carmona L, Costello R, Costello W, Gossec L, Grainger R, Hachulla E, Hasseli R, Hausmann JS, Hyrich KL, Izadi Z, Jacobsohn L, Katz P, Kearsley-Fleet L, Robinson PC, Yazdany J, Machado PM (2021) COVID-19 global rheumatology alliance; COVID-19 global rheumatology alliance consortium. Factors associated with COVID-19-related death in people with rheumatic diseases: results from the COVID19 Global Rheumatology Alliance physician-reported registry. Ann Rheum Dis. 27:annrheumdis-2020-219498. https://doi.org/ 10.1136/annrheumdis-2020-219498

7. Bodur H, Yurdakul FG, Çay HF, Uçar Ü, Keskin Y, Sargın B, Gürer G, Yurdakul OV, Çalış M, Deveci H, Aydın Y, Hizmetli S, Çevik R, Karahan AY, Sunar İ, Duruöz MT, Ecesoy H, Günendi Z, Toprak M, Şen N, Altıntaş D, Cengiz AK, Çağlayan G, Demir AN, Kaplan H, Ketenci S, Melikoğlu MA, Nayimoğlu M, Nas K, Sarıfakıŏglu AB, Sezer İ (2020) Familial Mediterranean fever: assessment of clinical manifestations, pregnancy, genetic mutational analyses, and disease severity in a national cohort. Rheumatol Int 40:29-40

8. Stella A, Lamkanfi M, Portincasa P (2020) Familial Mediterranean fever and COVID-19: friends or foes? Front Immunol 18(11):574593

9. Siu KL, Yuen KS, Castaño-Rodriguez C, Ye ZW, Yeung ML, Fung SY, Yuan S, Chan CP, Yuen KY, Enjuanes L, Jin DY (2019) Severe acute respiratory syndrome coronavirus ORF3a protein activates the NLRP3 inflammasome by promoting TRAF3-dependent ubiquitination of ASC. FASEB J $33: 8865-8877$ 
10. Livneh A, Langevitz P, Zemer D, Zaks N, Kees S, Lidar T, Migdal A, Padeh S, Pras M (1997) Criteria for the diagnosis of familial Mediterranean fever. Arthritis Rheum 40:1879-1885

11. Pras E, Livneh A, Balow JE Jr, Pras E, Kastner DL, Pras M, Langevitz P (1998) Clinical differences between North African and Iraqi Jews with familial Mediterranean fever. Am J Med Genet 13(75):216-219

12. Grasselli G, Zangrillo A, Zanella A, Antonelli M, Cabrini L, Castelli A, Cereda D, Coluccello A, Foti G, Fumagalli R, Iotti G, Latronico N, Lorini L, Merler S, Natalini G, Piatti A, Ranieri MV, Scandroglio AM, Storti E, Cecconi M, Pesenti A (2020) COVID19 lombardy ICU network. baseline characteristics and outcomes of 1591 patients infected With SARS-CoV-2 admitted to ICUs of the lombardy region Italy. JAMA 323:1574-1581

13. Richardson S, Hirsch JS, Narasimhan M, Crawford JM, McGinn T, Davidson KW; the Northwell COVID-19 Research Consortium, Barnaby DP, Becker LB, Chelico JD, Cohen SL, Cookingham J, Coppa K, Diefenbach MA, Dominello AJ, Duer-Hefele J, Falzon L, Gitlin J, Hajizadeh N, Harvin TG, Hirschwerk DA, Kim EJ, Kozel ZM, Marrast LM, Mogavero JN, Osorio GA, Qiu M, Zanos TP (2020) Presenting characteristics, comorbidities, and outcomes among 5700 patients hospitalized With COVID-19 in the New York City Area. JAMA. 323:2052-9

14. D'Silva KM, Serling-Boyd N, Wallwork R, Hsu T, Fu X, Gravallese EM, Choi HK, Sparks JA, Wallace ZS (2020) Clinical characteristics and outcomes of patients with coronavirus disease 2019 (COVID-19) and rheumatic disease: a comparative cohort study from a US "hot spot." Ann Rheum Dis 79:1156-1162

15. Pablos JL, Abasolo L, Alvaro-Gracia JM, Blanco FJ, Blanco R, Castrejón I, Fernandez-Fernandez D, Fernandez-Gutierrez B, Galindo-Izquierdo M, Gonzalez-Gay MA, Manrique-Arija S, Mena Vázquez N, Mera Varela A, Retuerto M, Seijas-Lopez A, RIER investigators group (2020) Prevalence of hospital PCR-confirmed COVID-19 cases in patients with chronic inflammatory and autoimmune rheumatic diseases. Ann Rheum Dis 79:1170-1173

16. Pablos JL, Galindo M, Carmona L, Lledó A, Retuerto M, Blanco R, Gonzalez-Gay MA, Martinez-Lopez D, Castrejón I, AlvaroGracia JM, Fernández Fernández D, Mera-Varela A, ManriqueArija S, Mena Vázquez N, Fernandez-Nebro A, RIER Investigators Group; RIER investigators group (2020) Clinical outcomes of hospitalised patients with COVID-19 and chronic inflammatory and autoimmune rheumatic diseases: a multicentric matched cohort study. Ann Rheum Dis. 79:1544-1549

17. Gianfrancesco M, Hyrich KL, Al-Adely S, Carmona L, Danila MI, Gossec L, Izadi Z, Jacobsohn L, Katz P, Lawson-Tovey S, Mateus EF, Rush S, Schmajuk G, Simard J, Strangfeld A, Trupin L, Wysham KD, Bhana S, Costello W, Grainger R, Hausmann JS, Liew JW, Sirotich E, Sufka P, Wallace ZS, Yazdany J, Machado PM, Robinson PC, COVID-19 Global Rheumatology Alliance (2020) Characteristics associated with hospitalisation for COVID19 in people with rheumatic disease: data from the COVID-19 Global Rheumatology Alliance physician-reported registry. Ann Rheum Dis 79:859-866

18. Xu C, Yi Z, Cai R, Chen R, Thong BY, Mu R (2021) Clinical outcomes of COVID-19 in patients with rheumatic diseases: a systematic review and meta-analysis of global data. Autoimmun Rev 17:102778. https://doi.org/10.1016/j.autrev.2021.102778

19. Schulert GS, Cron RQ (2020) The genetics of macrophage activation syndrome. Genes Immun 21:169-181

20. Van den Berg DF, Te Velde AA (2020) Severe COVID-19: NLRP3 inflammasome dysregulated. Front Immunol 26(11):1580

21. Bourguiba R, Delplanque M, Vinit C, Ackermann F, Savey L, Grateau G, Hentgen V, Georgin-Lavialle S (2020) Clinical course of COVID-19 in a cohort of 342 familial Mediterranean fever patients with a long-term treatment by colchicine in a French endemic area. Ann Rheum Dis. https://doi.org/10.1136/annrh eumdis-2020-218707

22. Haslak F, Yildiz M, Adrovic A, Sahin S, Koker O, Aliyeva A, Barut K, Kasapcopur O (2020) Management of childhood-onset autoinflammatory diseases during the COVID-19 pandemic. Rheumatol Int 40:1423-1431

23. Richter M, Boldescu V, Graf D, Streicher F, Dimoglo A, Bartenschlager R, Klein CD (2019) Synthesis, biological evaluation, and molecular docking of combretastatin and colchicine derivatives and their hCE1-activated prodrugs as antiviral agents. Chem Med Chem 19(14):469-483

24. Scarsi M, Piantoni S, Colombo E, Airó P, Richini D, Miclini M, Bertasi V, Bianchi M, Bottone D, Civelli P, Cotelli MS, Damiolini E, Galbassini G, Gatta D, Ghirardelli ML, Magri R, Malamani P, Mendeni M, Molinari S, Morotti A, Salada L, Turla M, Vender A, Tincani A, Brucato A, Franceschini F, Furloni R, Andreoli L (2020) Association between treatment with colchicine and improved survival in a single-centre cohort of adult hospitalised patients with COVID-19 pneumonia and acute respiratory distress syndrome. Ann Rheum Dis 79:1286-1289

25. Brunetti L, Diawara O, Tsai A, Firestein BL, Nahass RG, Poiani G, Schlesinger N (2020) Colchicine to weather the cytokine storm in hospitalized patients with COVID-19. J Clin Med 14(9):2961

26. Deftereos SG, Giannopoulos G, Vrachatis DA, Siasos GD, Giotaki SG, Gargalianos P, Metallidis S, Sianos G, Baltagiannis S, Panagopoulos P, Dolianitis K, Randou E, Syrigos K, Kotanidou A, Koulouris NG, Milionis H, Sipsas N, Gogos C, Tsoukalas G, Olympios CD, Tsagalou E, Migdalis I, Gerakari S, Angelidis C, Alexopoulos D, Davlouros P, Hahalis G, Kanonidis I, Katritsis D, Kolettis T, Manolis AS, Michalis L, Naka KK, Pyrgakis VN, Toutouzas KP, Triposkiadis F, Tsioufis K, Vavouranakis E, Martinèz-Dolz L, Reimers B, Stefanini GG, Cleman M, Goudevenos J, Tsiodras S, Tousoulis D, Iliodromitis E, Mehran R, Dangas G, Stefanadis C, GRECCO-19 investigators (2020) Effect of colchicine vs standard care on cardiac and inflammatory biomarkers and clinical outcomes in patients hospitalized with coronavirus disease 2019: the GRECCO-19 randomized clinical trial. JAMA Netw Open 1(3):e2013136

27. Lopes MI, Bonjorno LP, Giannini MC, Amaral NB, Menezes PI, Dib SM, Gigante SL, Benatti MN, Rezek UC, Emrich-Filho LL, Sousa BAA, Almeida SCL, Luppino Assad R, Veras FP, Schneider A, Rodrigues TS, Leiria LOS, Cunha LD, Alves-Filho JC, Cunha TM, Arruda E, Miranda CH, Pazin-Filho A, AuxiliadoraMartins M, Borges MC, Fonseca BAL, Bollela VR, Del-Ben CM, Cunha FQ, Zamboni DS, Santana RC, Vilar FC, Louzada-Junior P, Oliveira RDR (2021) Beneficial effects of colchicine for moderate to severe COVID-19: a randomised, double-blinded, placebocontrolled clinical trial. RMD Open 7:e001455

28. Nas K, Eryilmaz N, Geyik MF, Altaş A (2021) COVID-19 in patients with familial Mediterranean fever treated with colchicine: case based review. Rheumatol Int 41:811-817

29. Güven SC, Erden A, Karakaş Ö, Armağan B, Usul E, Omma A, Küçükşahin O (2021) COVID-19 outcomes in patients with familial Mediterranean fever: a retrospective cohort study. Rheumatol Int 41:715-719

30. Jorge A, D'Silva KM, Cohen A, Wallace ZS, McCormick N, Zhang Y, Choi HK (2021) Temporal trends in severe COVID19 outcomes in patients with rheumatic disease: a cohort study. Lancet Rheumatol 3:e131-e137

Publisher's Note Springer Nature remains neutral with regard to jurisdictional claims in published maps and institutional affiliations. 


\section{Authors and Affiliations}

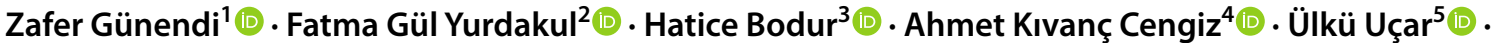

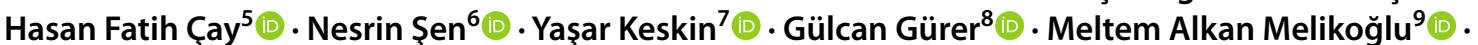

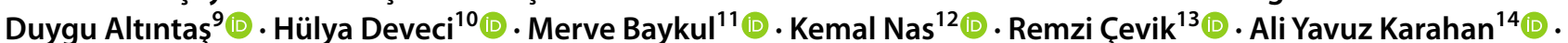

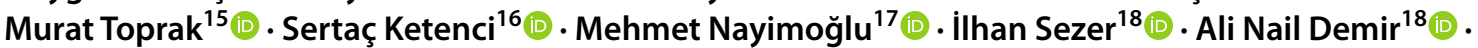

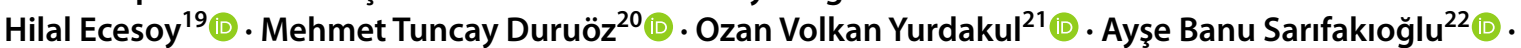 Şebnem Ataman ${ }^{23}$ (1)}

1 Division of Rheumatology, Department of Physical Medicine and Rehabilitation, Faculty of Medicine, Gazi University, Ankara, Turkey

2 Department of Physical Medicine and Rehabilitation, Ministry of Health Ankara City Hospital, Ankara, Turkey

3 Department of Physical Medicine and Rehabilitation, Faculty of Medicine, Ministry of Health Ankara City Hospital, Yıldırım Beyazıt University, Ankara, Turkey

4 Department of Physical Medicine and Rehabilitation, Faculty of Medicine, 19 Mayıs University, Samsun, Turkey

5 Department of Physical Medicine and Rehabilitation, Rheumatology Clinic, Antalya Training and Research Hospital, Antalya, Turkey

6 Rheumatology Clinic, Kartal Dr. Lütfi Kırdar Training and Research Hospital, Istanbul, Turkey

7 Department of Physical Medicine and Rehabilitation, Faculty of Medicine, Bezmialem Vakif University, Istanbul, Turkey

8 Division of Rheumatology, Department of Physical Medicine and Rehabilitation, Faculty of Medicine, Adnan Menderes University, Aydin, Turkey

9 Division of Rheumatology, Department of Physical Medicine and Rehabilitation, Faculty of Medicine, Atatürk University, Erzurum, Turkey

10 Department of Physical Medicine and Rehabilitation, Faculty of Medicine, Gaziosmanpaşa University, Tokat, Turkey

11 Department of Physical Medicine and Rehabilitation, Faculty of Medicine, Sakarya University, Sakarya, Turkey

12 Division of Rheumatology and Immunology, Department of Physical Medicine and Rehabilitation, Faculty of Medicine, Sakarya University, Sakarya, Turkey
13 Department of Physical Medicine and Rehabilitation, Faculty of Medicine, Dicle University, Diyarbakır, Turkey

14 Department of Physical Medicine and Rehabilitation, Faculty of Medicine, Uşak University, Uşak, Turkey

15 Department of Physical Medicine and Rehabilitation, Faculty of Medicine, Van Yüzüncü Yıl University, Van, Turkey

16 Rheumatology Clinic, Ministry of Health Manisa City Hospital, Manisa, Turkey

17 Department of Physical Medicine and Rehabilitation, Faculty of Medicine, Namik Kemal University, Tekirdağ, Turkey

18 Division of Rheumatology, Department of Physical Medicine and Rehabilitation, Faculty of Medicine, Akdeniz University, Antalya, Turkey

19 Department of Physical Medicine and Rehabilitation Rheumatology Clinic, Faculty of Medicine, Necmettin Erbakan University, Konya, Turkey

20 Division of Rheumatology, Department of Physical Medicine and Rehabilitation, Faculty of Medicine, Marmara University, Istanbul, Turkey

21 Department of Physical Medicine and Rehabilitation, Faculty of Medicine, Bezmialem Vakif University, Istanbul, Turkey

22 Department of Physical Medicine and Rehabilitation, Faculty of Medicine, Tekirdağ Namık Kemal University, Tekirdağ, Turkey

23 Division of Rheumatology, Department of Physical Medicine and Rehabilitation, Faculty of Medicine, Ankara University, Ankara, Turkey 